\title{
High School EFL Khmer Students' Challenges and Solutions in Learning English Letter Writing: A Case at a Vietnamese High School
}

\author{
Hong Chau Phu Thi ${ }^{1}$ and Cong Dan Thai ${ }^{2}$ \\ ${ }^{1}$ Department of English Teacher Education, School of Foreign Languages \\ Can Tho University, Can Tho City, Vietnam \\ ${ }^{2}$ School of Social Sciences and Humanities, Can Tho University, \\ Can Tho City, Vietnam
}

\begin{abstract}
This study was conducted at Chau Thanh high school in Kien Giang province, South of Vietnam in the school year 2019-2020 to investigate the difficulties and solutions of Khmer students while learning to write English letters from English textbook Grade 10 (Tiếng Anh 10) by the Vietnamese Education and Training (MoET). This research used an integrated research method including qualitative and quantitative methods. The quantitative research method was used to identify Khmer students' difficulties in writing skills. The qualitative research method is used to investigate Khmer students' solutions to their problems. The process of analyzing the results in turn was to analyze the results of the two letter writings, then the questionnaire analysis and finally the interview result analysis. The results showed that Khmer students had difficulty writing skills. These difficulties related to the Khmer students' ways of learning and teachers' teaching methods. Among these difficulties, the results indicated that most of the students participating in the study found it beneficial to understand and use English language skills and considered this to be the most important difficulty. The results also showed that Khmer students were interested and aware of the different solutions, in which they paid special attention to the teaching method of the teachers and regarded this as an effective solution. In addition, Khmer students also proposed other solutions related to the curriculum, textbooks, to name a few.
\end{abstract}

Keywords: Khmer students, English writing, English letters writing, challenges, solutions, Chau Thanh high school

\section{Introduction}

The Mekong Delta region, South of Vietnam has been considered the hollow region in English learning and teaching in Vietnam (Tai, 2011). Therefore, it is not surprising that many of Vietnamese teachers of English have always encountered a lot of difficulties when teaching English to Khmer students in Tra Vinh, Soc Trang, Tra Vinh, Bac Lieu Provinces, in the Mekong Delta, especially Kien Giang Province, where there is the highest number of Khmer students.

While teaching English to Khmer students in a high school in the Mekong Delta so far, the researcher has really found that there have been certain challenges to Vietnamese teachers in this approach. First, the influence of Khmer language including Khmer grammar, punctuation, word formation and word order in a sentence in English writing letters. Second, many of Khmer students have not had suitable English writing strategies and lacked of motivation in learning writing English letters. And finally, it is the traditional teaching method of Vietnamese teachers mainly focusing on teacher-centered, textbook-centered and test-centered that have negative effects on Khmer students' outcomes. What's more, based on the-end-of-year results and classroom observations, the researcher draws a conclusion that Khmer students have faced some challenges towards learning English namely learning strategies, motivation and Khmer students' English competency while they are learning with Vietnamese (Kinh) ones in a class, whose challenges are differed from those learning in a Khmer boarding school as previous researchers have conducted their studies so far. 
These challenges have affected the efficiency in teaching and learning English, which forces the researcher to construct a thesis entitled "A Study on High School EFL Khmer Students' Challenges and Solutions in Learning English Letter Writing: A Case at a Vietnamese High School" towards this situation with a view to enhancing the professional development towards EFL high school teachers and better English achievements of Khmer students.

This study tried to answer the following questions (1) What are the major challenges for Vietnamese EFL high school teachers and Khmer students in teaching and learning English Chau Thanh high school, Kien Giang Province? And (2) What are the possible solutions to the major challenges for Vietnamese EFL high school teachers and Khmer students in teaching and learning English at Chau Thanh high school, Kien Giang Province? presented as follows.

\section{Review of Literature}

\subsection{Writing skill in English}

The term "writing" is defined as a thinking process (Brown, 2001). Moreover, Al-Mutawa and Kailani (1989) stage that writing is a process that begins with a topic sentence and then ends with a conclusion sentence to close the problem. In this respect, Kutz, Groden, and Zamel (1993) agreed writing is a creative process characterized by the interaction of content and language and the use of language to explore new things outside of the known contents. Writing is a process that takes place over some time, even though it is a long one if one considers the stages of thought before writing a first draft (Silva and Harris, 1993). While Elbow (1973) in Brown (2001) reported that writing is a creative process including two stages. The first stage is the time for figuring out the meaning or idea. Next, the second stage is putting the meaning or ideas into the new language. According to Rivers (1981), writing is a way of conveying information or an expression of the original idea consecutively through a new language.

\subsection{Writing English letters}

Writing is a very broad category, it refers to the creation of text products. However, this study focuses on the writing ability of high school students. Letters at the high school level are divided into an informal letter and a formal letter.

\subsubsection{English informal letter}

As Surbhi from keydifferences.com, an informal letter is written to someone who the writers know fairly well. This type of letter can be usually used for some reasons such as conveying messages, news, giving advice, congratulating the recipient, requesting information, asking questions, ... This is a letter written to whom the writers are familiar with such as their friends, roommates or any other closed ones. Furthermore, an informal letter is used for a very close person therefore the language use in this kind of letter is usually friendly, and makes use of personal or emotional tone. Slang or colloquial terms, secret codes, abbreviations are used freely. However, this type of letter does not require professionalism, it depends on the familiar level between the writer and the recipient.

\subsubsection{English formal letter}

Based on keydifferences.com, the formal letter is strongly different from the informal letter. The formal letter is defined as a formal letter written in the professional language, with a prescribed format for a formal purpose. It can be used for many purposes such as recommendation letters, inquiry letters, complaint letters, cover letter and so on. There are a variety of reasons to use formal letters like a formal invitation, proposal, reference, making a complaint or inquiry, applying for a job. Moreover, letters in the area of business are formal, but vice versa is not possible. In terms of formal letters, three main types are usually used in reality. They are business letters, letters for outlining civic problems and job applications. This means that when writing a formal letter, the writer must follow the standard format. This format includes the sender's address, date, receiver's address, greeting, subject, the body of the letter, and closing the letter.

2.2.3. Writing paragraphs in English letters

The main body of a letter usually consists of 3 different paragraphs. The paragraphs in an English letter are also written as a paragraph in an essay or presentation. In the line of this issue, the paragraph has some definitions including Al- Hamash and Younis (1985), Oshima, Alice, Hogue, and Ann. (1999), Langan (2000) and Feist (1996). First of all, a paragraph is defined as a group of sentences concerned with one idea (Al- Hamash and Younis, 1985). In other words, there are many sentences and all of them support one idea that is staged in the topic sentence. Moreover, Oshima, Alice, Hogue, \& Ann. (1999) staged that a paragraph is considered as a basic organizational unit in a writing. This means that a paragraph can be as short as a sentence or as long as dozens of sentences. Therefore, the number of sentences in a paragraph is despised. Otherwise, the paragraph shouldn't be very long and it should have enough sentences to develop the main idea. And a paragraph should be 200 words (Langan, 2000). In other words, it includes a sentence as the topic sentence and some other sentences used to support the topic sentence.

\subsection{Writing English letters in the high school context}

Writing is one of the four most difficult English skills. In high school, this skill is also very difficult for students, and Khmer students are no exception. In Tiếng Anh 10 (Grade 10) , besides listening, speaking, reading and writing skills, students also learn about grammar and pronunciation. Writing 
skills account for a quarter of the total instruction time of the year. And students have English writing classes every week. In writing class, students learn from easy to difficult sequences. The writing program starts with writing each sentence individually. Students practice this through sentence matching exercises, combining individual components into complete sentences. The topic in this stage is usually about the past, or arranging the narrative sentences or filling in the gaps.

\subsection{Challenges of writing English letters in high school}

Some errors appear frequently in student writing. According to the report from the paper of exploration before conducting the questionnaire, Khmer students had different writing mistakes (errors), but generally, each student encountered at least or many of them. In the term of linguistics, these mistakes were called by name of word formation, word choice, spelling, organization, verb tense, punctuation, missing word, preposition, capitalization, verb formation, article, word order and subject/verb agreement, which would be described in detail in the Item 4- Results.

\subsection{English writing learning strategies}

Writing skill is not the same with speaking skill, it requires learners to follow some different rules or orders of steps to get perfect writing products, but in speaking skills, learners can speak freely. In the term of English writing learning strategies, Susan Verner in busyteacher.org reported that there are 5 phases including 13 simple strategies for helping English language learners throughout the writing process, namely prewriting, organizing, writing and editing and rewriting.

\subsection{English letter writing learning strategies towards solutions}

As mentioned above, many difficulties have appeared in students' writing and they are a great obstacle for developing students' ability to write perfectly. Therefore, it is necessary to study these types of errors and find solutions. Sunthornwatanasiri (2011) agreed that it is necessary to find solutions for writing errors because the results after analysis show that the application of error analysis strongly enhanced students' English writing competence. Besides, Zafar (2016) confirmed that students' accuracy of the use of verb tenses in writing skill was increased based on the technique of error analysis. Numerous studies have been conducted to find solutions to students' mistakes in writing skills. The solutions are focused on improving the effective teaching of writing skills by improving teaching methods. Besides these other solutions give advice based on student's skill development. In line with this issue, active learning is presented as an optimal solution for improving students' writing ability. Next
Amani, E, H, E, M (2019) has given a specific and detailed way to solve this problem effectively. These workarounds include such as : (1)Teachers need to encourage students to write a coherent composition, (2) Teachers have to use constructive feedback and follow-up strategies to improve students' writing skill improvement, (3) Students should be brainstormed to develop their essay writing skills, (4) Teachers should give the opportunity and enough time for students to practice writing skills, (5) Teachers should give more different homework compositions and extensive exercises, (6) Collaborative writing activities should be used to encourage learners to write the composition, and (7) Teachers should make more encouragement and moderation in controlling students' writing tasks.

\subsection{The difference between Khmer and English}

For English learners, they face the most challenges for the difference between their target language and their native language. When they are not aware of the difference, the sure result they encounter is failure. Therefore, it is essential to understand and have knowledge about the differences between the two languages. Concerning this, Swan and Smith's (1987, 2001) who have studied more than 20 languages asserted that English has some opposites and differences for another target language. In this case, the Khmer language is no exception. According to Bounchan and Moore (2010), Khmer has many vocabulary words borrowed from Vietnamese, Chinese, Thai, French, and English. Therefore, Khmer is not a tonal language. And this makes it difficult for Khmer speakers to use English. The differences between Khmer and English come from phonology (consonants), grammar, and orthography. In particular, grammar is the biggest difference.

\section{Materials and Methods}

\subsection{Material}

This study used units in the English textbbok 10-Tiếng Anh 10 ( Grade 10) from the MoET for Khmer students' two letter writing papers to discover their mistakes leading to challenges and solutions to better English writing letter strategies with the help of their EFL high school teachers.

\subsection{Research methods}

For the purpose of getting Khmer students' challenges in learning English letter writing, the total of 65 high school students, including 53 Khmer students (21 males and 32 females) and 12 Kinh "Vietnamese" ones ( 6 males and 6 females) from 4 classes (180 students) of Grade 10 at a high school in Chau Thanh high school, aged from 16-17, after signing in a consent letter, were invited to sit for two letter writing papers based on the English textbook- 
Tiếng Anh 10 ( Grade 10) from the MoET, whose mistakes were counted in their letter writing styles and body letters and letter organization. Also, for the aim of getting Khmer students' challenges in learning English letter writing, the same number of participants writing the two letters, that means, 53 Khmer students (21 males and 32 females) and 12 Kinh "Vietnamese" ones (6 males and 6 females) were delivered a questionnaire to express their ideas in their letter mistakes, teaching methodology from EFL teachers and their learning strategies in learning how to write English letters and their learning with their classmates, Kinh "Vietnamese" ones after writing the two letters as well. In this study, $5 \mathrm{EFL}$ high school teachers ( 2 males and 3 females) out of 10 at Chau Thanh high school, aged 25-40, holding BA degrees in Teaching English as a foreign language (TEFL), among of whom were 3 Vietnamese teachers and 2 Khmer teachers ( over 10 years of teaching) and 8 students, including 6 Khmer students and 2 Vietnamese students wiere asked to join 3 sets of semi-structured interview, in which one was for EFL teachers to make sure their Khmer students 'challenges and solutions with their guidance and teaching them with English letter writing in Tiếng Anh 10 (Grade 10).

\section{Results}

\subsection{Results from Khmer students' two writing papers}

To answer research question 1 about the common mistakes that Khmer students made while writing English letters in English program 10 "What are high school EFL Khmer students' challenges having in learning English letter writing?", two writing papers were conducted at two different times. The purpose of the disruption is because the researcher wanted to verify whether the errors that the Khmer students encounter were temporary or fixed. After the writing papers were thoroughly and deeply analyzed by two teachers who did not teach the Khmer students, many mistakes were detected in the letters including 1 st and 2 nd edition. The errors relate to the format of letter errors, missing of words including instruction sentence, verb tense, word choice, word form, word order and spelling. The number of errors varied in that the format of letter error was the most severe and the worst.

\subsubsection{Mistakes on the format of the letter}

The first writing paper with $53 \%$ error rate was slightly higher than $47 \%$ of the second time. Khmer students violated the error of writing missing part or more of the required part in a letter. Specifically, students often lack or not write date. Students also did not show the reason for writing letters, the greeting in the letterhead and the way of goodbye at the end of the letter. However, the most important and most common mistake was that the writing was not clearly organized. In other words, students only wrote sentences and put them together but did not divide paragraphs for different ideas. This happened at two times.

In the first time of writing, Khmer students' errors in the first 53 writing papers were classified into many different categories. Only 3 articles were in the right format but still had many errors. Meanwhile 2 students left the blank papers. It means that the two students could not write any words. And there was one writing that was out of the topic. Moreover, 15 other writings were only completed with a few sentences even a few words. The errors on the format of the letter occurred on 32 writings left although they followed the topic and had some writing mistakes.

In the second time, students seemed more familiar with the actual writing situation, so they understood the layout and method of a letter more. However, Khmer students' did not still write the address, date, and lack of greeting at the end of the letter and do not divide the paragraph clearly and suitably. In 53 second writing papers, there were not the letters that did not finish fully and went out of the topic. This was a good sign is that students made some progress. There were good 11 articles that demonstrated the increase students' ability to write when they followed the topic fully and limit the errors at a very low rate.

\subsubsection{Mistakes on missing words}

Writing sentences with missing words was the next major mistake after the format of letter. This error involved writing an incomplete sentence. One kind of this error was that Khmer students only wrote subjects and verbs or only write the subject or predicate of the sentence without the rest. The other form of this error was that an English sentence written missing a word or a few words. Accordingly, students often lacked the subject, verb, or preposition. This error occurred quite often in both times of writing the letter, but the level at the first time was quite high when 44 writings accounted for $54 \%$ compared with 38 writings of the 2 nd time with $46 \%$. It's clear that this error rate in the last time reduced a little compared to the previous time. One explanation for this was that students' understanding of the English sentence structure has a positive shift after practicing writing.

\subsubsection{Mistakes on word order}

At the next position after the errors on missing words was the word order error. This was a type of error that Khmer students did not follow the order of words in English sentences. This meant that students did not put the word at the right position in English. In most Khmer students' writings, the error of placement between words in the subject including 
many words appeared very often. This percentage was $52 \%$ in the first writing and this rate decreased a bit with $48 \%$ in the second writings. A most suitable explanation for this error was that Khmer students did not have sufficient knowledge about the location of words in English sentences. On the other hand, basing too closely on Khmer native language also led to incorrect placement of English words.

\subsubsection{Mistakes on word form}

The fourth position in error categories was word form errors. Compared to other errors, the number of Khmer students' writings of this error decreased slightly with 36 writings $(55 \%)$ in the first time and continued to decrease to 30 writings $(45 \%)$ in the next time. This was a type of error where the writer displayed an incorrect form of the word type. In Khmer students' writings, the word form error was often about adding "s" in words that did not need "s". And the writer also forgot to add "ing" to the verb when the verb followed the word "when" or was in gerund form. Or the writer added "ing" to the verb that followed "will" where the sentence needed the form infinitive without "to".

\subsubsection{Mistakes on verb tense}

Ranked the third place in all errors in the writing of Khmer students was the error of grammar which was mainly about the tense in English. Khmer students' writing had in common when violating time mistakes and writing the wrong verb forms. This meant that Khmer students did not know or misidentify the time that action took place, leading to misidentification. And when they determined the time, they wrote the wrong verb form. The rate of this error in the second time was higher than the previous time with $55 \%$ compared to $45 \%$. In other words, the more Khmer students wrote, the more they used the wrong English tense. A suitable explanation for this error was that Khmer students used their native language to convey the idea. Another explanation was that they had a solid knowledge of tenses in English.

\subsubsection{Mistakes on word choice}

Another high rate error is word choice. This was an error where the writer chose the wrong word or phrase for a certain position in the sentence. This error rate in the total of $53 \mathrm{Khmer}$ writing papers was $55 \%$ (33 writing papers) at the first time. The ratio then decreased slightly when it was reduced to $45 \%$ (27 writing papers) for the second time. This showed that Khmer students made little progress in using the appropriate word in sentences when they have been practiced many times.

\subsubsection{Mistakes on spelling}

The last type of errors found among Khmer students' writings were spelling errors. Although this error rate was very low, only 7 errors in the $1^{\text {st }}$ time and increased to 10 errors in the $2^{\text {nd }}$ time, but this also showed that the vocabulary ability of Khmer students was still limited. This was due to the fact that Khmer students had little chance to practice writing English words or sentences, which led to forgetting or due to careless writing. Spelling errors related to the word that was written in the wrong letters or was not written clearly.

\subsection{Results from Vietnamese writing papers}

Also related to the violation of Khmer students while writing the letter, 12 Vietnamese students taking the same classes with Khmer students were randomly selected to analyze the types of errors in their letter writing. The purpose of this work was that the researcher wanted to prove whether or not the relationship or interaction is in the results of learning English writing skills between Khmer and Vietnamese students. From this result, the researcher would suggest appropriate solutions. Results from 24 writing papers of 12 Vietnamese students in both times showed a quite unexpected thing. Four out of 24 writings could not complete the content of the letter. In other words, these 4 Vietnamese students could only write a few words or sentences. The remaining 20 writings all completed the content of the letter. However, there were one or more errors in their writings like those in the letter of Khmer students. In all 24 letters Vietnamese students did not fully show the letter form.

4.3. The quantitative results of the questionnaire

The result of the questionnaire aims to answer the research question (1) What are high school EFL Khmer students' challenges having in learning English letter writing? And (2) What are possible solutions to high school EFL Khmer students' challenges in learning English letter writing?

Table 4.2. The results of Descriptive Statistics of the Mean score of the clusters on the questionnaire

\begin{tabular}{lccc}
\hline \multicolumn{1}{c}{ Clusters } & Min & Max & Mean \\
\hline $\begin{array}{l}\text { 1A. Difficulties in } \\
\text { learning English writing } \\
\text { skills of Khmer students }\end{array}$ & 3.64 & 5.00 & $\mathbf{4 . 3 2 7 5}$ \\
\hline $\begin{array}{l}\text { 1B. Challenges in } \\
\text { learning English writing }\end{array}$ & 3.67 & 5.00 & $\mathbf{4 . 2 8 3 0}$ \\
strategies of Khmer \\
students
\end{tabular}




\begin{tabular}{llll}
\hline Khmer students & & & \\
\hline $\begin{array}{l}\text { 2B. Solutions to learning } \\
\text { English writing strategies }\end{array}$ & 3.50 & 5.00 & $\mathbf{4 . 1 6 6 7}$ \\
of Khmer students & & & \\
\hline 2C. Solutions to teaching & 3.40 & 5.00 & $\mathbf{4 . 2 0 3 8}$ \\
methods of EFL high & & & \\
school teachers on & & & \\
learning to write English & & & \\
letters of Khmer students & & \\
\hline Total mean: $\mathbf{4 . 2 7 9 2}$ & & \\
\hline
\end{tabular}

The data in Table 4.2 showed that the Mean score of the questionnaire $(\mathrm{M}=4.2792)$ was high. This number indicated that Khmer students had the positive thinking and high agreement with different aspects of challenges and solutions in learning writing English letters. Khmer students' challenges in learning English writing skills got the highest mean score with $\mathrm{M}=4.3275$. This indicator showed that participants agreed and paid much attention to their challenges. They also assessed it was an important factor that strongly influenced their learning results. Following this was difficulties in teaching methods of writing English letters of EFL high school teachers with $\mathrm{M}=4.3113$, solutions to learning English writing skills of Khmer students with $\mathrm{M}=4.2864$, challenges in learning English writing strategies of Khmer students with $\mathrm{M}=4.2830$, solutions to teaching methods of EFL high school teachers on learning to write English letters of Khmer students with $\mathrm{M}=4.2038$ and solutions to learning English writing skills of Khmer students with $M=4.1667$. It could be seen that all aspects had high levels of index. These indicators showed that participants appreciate and agree with the items in the questionnaire.

After collecting the statistics from respondents, the questionnaire was checked the reliability to make sure that the data from it was valuable in analyzing. SPSS Scale Test was run to test the reliability of the questionnaire. Each cluster ( Table 4.1) in the questionnaire provided a different aspect of Khmer students' challenges on learning writing English letter. Therefore, understanding the participants' views of each cluster helped to understand better their thoughts and needs about these problems. Moreover, comparing participants' level of perception in the clusters provided a specific picture of the learner's opinions. This helped the researcher to clearly understand what factors were appreciated, which factors made it difficult for the learners
Table 4.1. Comparison of clusters of Khmer students' challenges in English letter wriing

Paired Samples Test of challenges

\begin{tabular}{lcr}
\hline \multicolumn{1}{c}{ Clusters } & Mean & $\begin{array}{c}\text { Sig. (2- } \\
\text { tailed) }\end{array}$ \\
\hline $\begin{array}{l}\text { Challenge1A }- \\
\text { Challenge1B }\end{array}$ & .04447 & $\mathbf{. 2 9 9}$ \\
\hline $\begin{array}{l}\text { Challenge1A - } \\
\text { Challenge1C }\end{array}$ & .01617 & $\mathbf{. 7 7 2}$ \\
\hline $\begin{array}{l}\text { Challenge1B - } \\
\text { Challenge1C }\end{array}$ & -.02830 & $\mathbf{. 5 5 0}$ \\
\hline
\end{tabular}

Similarly, understanding which resolution was more important and more effective would help improve the mistakes of Khmer students. Therefore, the comparison of clusters in Khmer students' solutions was very necessary. The solutions included 3 clusters: 2A solutions for learning English writing skills of Khmer students, 2B solutions for learning English writing strategies of Khmer students and 2C solutions through teaching methods of teachers on learning to write English letters of Khmer students.

Table 4.3: The result of Paired Sample TTest of the solutions of Khmer students' in learning writing English letter

Paired Samples Test of solutions

\begin{tabular}{lcc}
\hline \multicolumn{1}{c}{ Clusters } & Mean & \multicolumn{1}{c}{$\begin{array}{c}\text { Sig. (2- } \\
\text { tailed) }\end{array}$} \\
\hline $\begin{array}{l}\text { Solution2A - } \\
\text { Solution2B }\end{array}$ & .11978 & $\mathbf{. 0 0 5}$ \\
\hline $\begin{array}{l}\text { Solution2A }- \\
\text { Solution2C }\end{array}$ & .08268 & $\mathbf{. 0 8 6}$ \\
\hline $\begin{array}{l}\text { Solution2B }- \\
\text { Solution2C }\end{array}$ & -.03711 & $\mathbf{. 4 8 3}$ \\
\hline
\end{tabular}

As illustrated in Table 4.3, a Paired Sample TTest was run to test whether the difference of Khmer students' solutions in learning English writing letter in terms of clusters $2 \mathrm{~A}, 2 \mathrm{~B}, 2 \mathrm{C}$. The result showed that the Sig values (Sig. (2-tailed)) of clusters $2 \mathrm{~B}$ and $2 \mathrm{C}(\mathrm{p} 2=0.086, \mathrm{p} 3=0.483)$ were higher than 0.05 $(p>0.05)$. It would be claimed that there was not a significant difference in Khmer students' challenges in learning English writing letter between cluster 2A and $2 \mathrm{C}, 2 \mathrm{~B}$ and $2 \mathrm{C}$. However, the Sig values (Sig. (2-tailed)) of clusters $2 \mathrm{~A}$ and $2 \mathrm{~B}(\mathrm{p} 1=0.005)$ was lower than $0.05(\mathrm{p}<0.05)$. It would be claimed that there was a significant difference in Khmer students' solutions between cluster $2 \mathrm{~A}$ and $2 \mathrm{~B}$. The next table would explain the difference in detail. 


\subsubsection{The qualitative results of the questionnaire}

The questionnaire for this study included two main parts: Part 1 was about difficulties in learning to write English letters, and Part 2 discussed the solutions corresponding to these problems. Each section was divided into 3 clusters and each cluster ended with an open-ending question. This gave participants the opportunity to express their specific ideas in more detail. And the followings are the opinion of the participants.

Regarding the difficulties in learning English writing skills of Khmer students. 44 participants said that they had the difficulty in displaying the form of the letter when they chose "I often get an error when writing a dot". "instead of a comma", "in a greeting. For example: Dear Xayrot". This was consistent with evidence from their two writing papers when most of the writings had a form of letter error. While 37 other participants showed that they did not often write the reason for writing a letter and this made the letter unclear and unkind. Besides, 29 respondents said that they did not know or did not use many different ways of saying goodbye because they chose "I usually only use a goodbye for all letters. For example, Best, ". Other voted also showed that they made a mistake in signing their name when 20 participants chose "I usually sign instead of writing the name at the right of the letter ".

In term of challenges in learning English writing strategies of Khmer students, It is highlight that students complained that they did not practice writing a lot because there was not enough time when 48 participants chose "I don't practice writing English because I have very little time". This resulted in their writing skills was not improved. Next, the difficulties related to textbooks ranked second position when the rating for "I did not fully understand the types of exercises to write English letters in English books 10" and "the writing exercises of English letters in textbooks are not diverse, so I have difficulty writing different types of letters" respectively 38 and 37 turns. It could be seen that Khmer students thought that textbooks were one of the important factor affecting their writing skills. In that case, the cooperation and mutual assistance between Vietnamese and Khmer students was less important when there were only 11 votes "I don't have the help from other Khmer and Vietnamese classmates".

Also related to the challenges of Khmer students in writing English letters, the teaching method of teachers' writing English letters was also a factor that influenced students' academic performance. This is illustrated more evident in this study with 39 votes for "Teachers spend less time for students to practice writing English letters in class". This once again strengthened that the practice strongly influenced the outcome of writing English letter. A little less selective regarding the teaching and delivery of assignments in a teacher's textbook because 36 participants thought that taking the task would help them improve when they chose "Some teachers do not return homework (letter writing) to students, so I don't know what my mistakes are" and 29 participants said "I was not taught all kinds of tasks after the lesson in learning to write English letters". The remaining factor was related to the facilities when 29 participants said that "The school facilities are not evenly (classrooms, computers, the Internet ...) interferes with learning English," which posed enough ideas to challenges.

\subsection{Interview results}

\subsubsection{The interview results of EFL high} school teachers

The semi-structured interview was conducted during the eighth week. Five EFL teachers consisted of 3 Khmer teachers (including 2 males and one female) and 2 Vietnamese teacher (including one male and on female) were chosen stratified. The questions of the interview included two versions which consisted of the Vietnamese version and English version. Five teachers were interviewed in the same time and all of them used Vietnamese to answer the questions. The data from the interview was interpreted into English with the support of supervisor.

In term of challenges in learning English letter writing, all of five teachers agreed that teaching writing skills was their most challenges. This was clearly shown by the teachers' answers. As Khmer teacher 1 said "I think writing skills is the hardest". Or this was confirmed by the Vietnamese teacher 1 "Writing is the hardest to teach me". The reason for this was to use the inappropriate teaching methods, a lack of understanding of English cultureand a lack of time for lesson planning and teaching. As reported by the Vietnamese teacher 1 "Because to complete the writing lesson, I have to spend a lot of time to prepare the lesson, then correct the lesson. And the children also take a lot of time to study and progress". While Vietnamese teacher 2 said that "Because it requires both the writer and the teacher to have a deep understanding of English culture, but I live in Vietnam with little chance to learn it." And Khmer teacher 1 "Because this skill requires teachers to have appropriate teaching methods".

\subsubsection{The interview results from Khmer and Vietnamese students \\ Interview results from six Khmer students carefully analyzed showed that all of them thought it was necessary to learn writing skills in high school. This was evidenced by participant 3 "I feel needed" and participant 6 "Yes, I feel it is necessary". All the reasons were given that they felt the need to learn English because of the high school graduation exam.}


As participant 2 said "Because it can help me write a lot of things when I take the test". Participant 4 affirmed "Because doing well in grade 10 will be the foundation for 11 and 12 years". Only participant 1 thought that English have learnt to communicate "Because it is very important whether or not you later go to university, you still need to know English to communicate," which exposed all English writing strategies.

\section{Discussions}

Results from two letter writing, questionnaires, and results from teacher and student interviews showed that Khmer students really had difficulty writing in Grade 10 in high school. It is safe to say that letter writing is the most challenging skill for Khmer students. This was also confirmed by Vuong (2013). In his research, Khmer students had difficulty in English language skills when writing English letters. However, within the scope of this study, specific results showed that Khmer students only really have difficulty in the format of the letter, missing words, word order, word form, verb tense, word choice, spelling. It could be seen that Khmer students did not violate all types of errors in using English. They only focused on the 7 English errors above. Out of these errors, the format error was the worst. The proof is that all the letters of the two writing letters occurred that the situation in which the students were unable to complete the letter format in the form and the content. Most of the students only wrote a few sentences, only a few completed the content of the letter, but all the Khmer students did not complete the form of the letter. They made mistakes about the greeting at the beginning and the closing part of the letter, the way of punctuation (commas, periods ...), the messy way of expressing the ideas in the letters.... The reason for this may come from the lack of practice opportunities leading to the lack of proficiency in the letter form. Differences between English and Khmer also affected this. In Khmer language, punctuation is not used so when writing in English, children are often confused and make mistakes. This just shows a difference and shows the similarities between Khmer students and students in other regions. Moreover, the difference between the two languages, Khmer and English, is the first major cause of errors in the writing skills of Khmer students. This difference comes from the difference in usage of words, phrases, sentences, the usage of tenses and phonology between the two languages.

The second biggest challenge related to teachers. The results of interviews and questionnaires showed that the teacher's writing teaching method is a problem. This was confirmed by the student's participation in answering the questionnaire and from the teacher who teaches the $10^{\text {th }}$ grade curriculum. Surveyed result showed that the teaching method was not creative and not appropriate. This also contributed to students and make them not interested in writing skills. The teachers applied too much mechanical the teaching techniques but did not understand the background as well as the culture and purpose of learning English of Khmer students made students feel that learning English was just to cope with exams without having real love. This is similar to other studies such as Borich (2006), Consortium Global Education (2006), and Spatt, M., Alan, P., \& Melanic, W. (2005). These studies suggested that applying the appriciate and creative approach to the appriciate context will be of greater benefit than applying exactly what teachers have trained in a teacher's classroom or a textbook.

Similarly, the motivation or real need for learning English in general and the writing skills in particular for Khmer students is almost none. This is clearly shown in the results collected from students and teachers. It can be affirmed that learning English by Khmer students' favorite is not available. Concerning how to solve difficulties in learning to write, all participants in this study agreed that improving teaching methods is the best and most effective solution. This means that the teaching methods that teachers are trained in their program must be applied in Khmer classes more scientifically and logically. In other words, teachers should not apply rigidly and mechanically teaching techniques. Because this makes students feel that learning English is a mandatory thing and is not their favorite. Students will not be interested with the same tchniques in different classes. According to student reports, teachers often focus on teaching grammar, vocabulary or reading comprehension because these things are included in graduation exams and help students pass exams. And teachers often keep this teaching method.

Regarding the awareness of participants' solutions to errors in learning English writing skills at grade 10 in high school. The workarounds also revolve around the errors that were analyzed above. For the viewpoint on the differences between the two languages, raising the awareness of the learner is the best solution. To do this well, the role of the teacher becomes important.

The second solution is to make the writing method animate. Teachers shuold avoid teaching in a way that lasts a long time in a class. According to the results of the interview and questionnaire, teachers can use games, outdoor activities ... Teachers also need to give different types of exercises to give students more opportunities to practice. Because a lot of practice helps students master their writing and language skills. This is consistent with the results from Borich (2006). These studies have confirmed that teaching methods seriously affect and account for a high proportion of the success or failure of English learners and positive, creative teaching 
methods will bring high efficiency. Moreover, improving the motivation to learn English by improving students' understanding of the importance of English in their work and life. Good examples of success at work plus reputation are an effective example. This is similar to Ruth (2008), Keller (1984). Making students feel motivated will help them gain the strength to overcome difficulties and achieve high academic results.

\section{Conclusions}

From the results of the above analysis, main findings have been made. Khmer students have a really hard time learning to write English letters, especially when it comes to letter form errors. The differences between the two languages are the biggest difficulty and if this problem is solved, it will be highly effective in learning the writing skills of Khmer students. The method of teaching writing skills plays an important role and directly affects the learning outcomes of Khmer students. Motivation also has a strong impact on whether or not English learning and English writing results are effective. Improving and improving these issues will bring positive results in teaching and learning to write English letters in high school.

Through an in-depth analysis of challenges and how to address these difficulties from two letter writing papers, questionnaires and semi-structured interviews, some key findings were discovered.

1. Khmer students really have difficulty in writing letters when almost all of the 2 letter writing papers showed errors in writing skills. In which the failure to complete the letter was the biggest error.

2. Other errors in vocabulary, grammar, or sentence structure also appeared quite often, indicating that Khmer students did not have sufficient knowledge about English language linguistic.

3. The awareness of the challenge of writing skills was the same for male and female participants, and for students with different years of English learning.

4. Most Khmer students made the mistake of not completing the letter. This is a very serious mistake because they showed that the writer was not knowledgeable about writing letters and how to correctly write the letter form.

2. Practice strongly affected writing results when a majority of participants complained that their lack of practice at home and in class strongly affected their writing results.

5. Writing exercises in textbooks directly affected the learning results of this skill of Khmer students.

6. Facilities such as schools, classrooms, internet, etc. needed to be considered and adjusted to suit the learning characteristics of Khmer students because more than half of the participants think that schools and classrooms have not been invested and have affected their writing skills.

7. All 3 elements of skills, learning methods and teaching methods of teachers had the same influence on Khmer students.

8. Among solutions, collaborative learning in class to improve the ability of vocabulary and phrases according to context and topic, not learning individual words or phrases was considered an effective solution.

9. Khmer students thought that studying the letter form before writing helped them to write the right letter form and better.

10. Studying by pairs or groups with other Khmer students or Vietnamese students helped Khmer students improve their ability to self-study and of vocabulary in writing letters.

11. Practice writing letters a lot through exercises and teachers' tasks helped Khmer students identify their weaknesses so that they will improve for the better.

12. Factors outside teaching methods and learning strategies such as culture and facilities are also effective solutions.

\section{Acknowledgments}

The researchers would, first, like to express their sincere thanks to lecturers at Can Tho University (CTU) Vietnam, especially those at School of Social Sciences \& Humanities (SSSH), and School of Foreign Languages (SFL), CTU, for their teaching and supervisions towards the Master Program in Teaching English to Speakers of Other Languages (TESOL) and the researcher's MA classmates of Cohorts 23, 24 and currently 25. Second, their great thanks would come to high school EFL teachers and Khmer students and Vietnamese ones at Chau Thanh high school, Kien Giang Province, Vietnam for their kind co operations to the research through the questionnaire, interviews and classroom observations. And last but not least, their deep thanks would go to IJASRM journal board for this paper to be published to the public, especially those interested in teaching and learning English in Vietnamese educational levels on the way to the regional and global integration.

\section{References}

[1] Al-Mutawa, N., \& Kailani, T. (1989). Methods of Teaching English to Arab Students. London: Longman.

[2] Al-Hamash, I. K. \& Younis, H. (1985). Principles and Techniques of Teaching English as a Second Language, Al-Shaab Press.

[3] Amani, E, H, E, M (2019). Investigating EFL students' problems in writing skill at secondary level: A case Study of EFL Students at Secondary Schools - Gezira 
State - Hasaheisa. Faculty of Education. University of Albutana. Sudan

[4] Brown, H. D. (2001). Teaching by principles: An interactive approach to language pedagogy (2nd ed.). New York: Addison Wesley Longman.

[5] Borich, G, D. (2006). Educational Psychology. A contemporary approach. A University of Texas at Austin.

[6] Bounchan, S., \& Moore, S. (2010). Teaching Practice Khmer Learner English: A Teacher's Guide to Khmer L1 Interference. Language Education in Asia, 2010, 1(1), 112-123. http://dx.doi.org/10.5746/LEiA/10/V1/A10/ Bounchan_Moore

[7] Consortium Global Education. (2006). Professional training for English Instruction. CGE.

[8] Elbow, P. (1973). Writing without teachers. New

[9] York: Oxford University Press.

[10]Feist, B. (1996). Applied Communication Skills: Writing Paragraphs. Cambridge Adult Education.

[11] Kutz, E., Groden, S., \& Zamel, V. (1993). The Discovery of Competence: Teaching and learning with diverse student writers. Portsmouth, NH: Boynton/Cook Publishers.

[12] Keller, J, M. (1984). The use of the ARCS model of motivation in teaching training. In Shaw, K., \& Trott, a, J., (Eds), Aspects of educational technology, volume 17. Staff Development and Career Updating, Kogan Page. London.

[13]Langan, J. (2000). College Writing Skills with Readings. $\left(5^{\text {th }}\right.$ ed). London: McGraw Hill.

[14] Oshima, Alice, Hogue, \& Ann. (1999). Academic Writing Skill ( $3^{\text {rd }}$ ed). New York: Longman.
[15] Rivers, W, M. (1981). Teaching Foreign Language Skill. Washington: The University of Chicago.

[16] Ruth, W, M, H. (2008). Motivation to learn English and age difference. The case of Chinese immigrant. The Hong Kong Institute of Education.

[17] Swan, M. \& Smith, B. (2001). Learner English: A teacher's guide to interference and other problems (2nd ed). Cambridge: Cambridge University Press.

[18] Silva, T. \& Harris, M. (1993). Tutoring ESL Students: Issues and Options. College Composition and Communication, 44(4): 525-537.

[19] Sunthornwatanasiri, W. (2011). Application of Error Analysis to Enhance English Writing Competence of the Students Majoring in Business English in the Faculty of Business Administration at Rajamangala University of Technology Rattanakosin.

[20] Spatt, M., Alan, P., \& Melanic, W. (2005). The TKT teaching Knowledge Test Course. Cambridge University Press.

[21] Tai, V, V. (2011). Khó khăn của học sinh Khmr khi học tiếng Anh và cách khắc phục. Tạp ch1i Giáo Dục số 254 (kỳ 2-1/2011).

[22] Vuong, M, D,. Dan, T, C,. and Chau, P, T, $\mathrm{H}$. (2017). An investigation into common mistakes in paragraph writing of the firstyear English-majored students: A case study in Can Tho University, Vietnam. Journal of Education Naresuan University, (19) 4, 2017.

[23]Zafar, A. (2016). Error Analysis: A Tool to Improve English Skills of Undergraduate Students. Procedia-Social and Behavioral Sciences, 217, 697-705. Retrieved from https://doi.org/10.1016/j.sbspro.2016.02.12 2 